\title{
Brief Overview of Intelligent Education
}

\author{
Tiejun Shao, ${ }^{1 *}$, Jianshe Zhou ${ }^{1,3}$ \\ ${ }^{1}$ Capital Normal University, Beijing 100048, China \\ ${ }^{2}$ North China Institute of Science and Technology, Langfang 065201, China \\ ${ }^{3}$ Research Center For Language Intelligence of China, Beijing 100048, China \\ *Corresponding author: Tiejun Shao,2180101027@cnu.edu.cn
}

\begin{abstract}
Intelligent Education uses AI technology as a means in the education ecology to promote the automation and intelligence of education and teaching. It reshapes the education ecology, adding AI things to the traditional education ecology that dominated by teachers and students. Although IE technology is widely used, there is little discussion about a comprehensive overview of IE. The goal and connotation of IE is discussed. Meanwhile, the emotional, ethical, AI technology as well as supervision and management perspectives in IE are discussed too. The core goal of IE is putted forward that is human-oriented and individualized development of students is. Finally, the education ecology with dual-teacher collaborative in intelligence education was proposed.
\end{abstract}

Keywords: Artificial intelligence; Intelligent education; Emotion analysis

Publication date: August 2021; Online publication: August 30, 2021

\section{Introduction}

On the China Artificial Intelligence Conference in 2019, it was mentioned that the greatest value of artificial intelligence lies in empowerment. By combining with various application scenarios and related industries, AI will bring changes in the industrial field. Among many fields, education will be one of those areas where AI technology is applied firstly. The empowerment of AI technology ${ }^{[1]}$ can solve some inherent problems in the education field to a large extent, and greatly promote the reform and innovation of education. With the application of AI technology, we can obtain fair and high-quality teaching. Lifelong learning for all individuals can be realized.

\subsection{Conception of IE}

IE is a combination of AI technology and education. With the development of AI technology, its application has been widely used in various stages of teaching scenes, but the specific concept of IE is still inconclusive. The "Blue Book of Intelligent Education Development (2019)" puts forward: Intelligent Education is based on intelligent technologies such as AI and big data, with learners as the center, building an intelligent education environment with contextual awareness, ubiquitous interconnection, data integration, and business collaboration. Briefly understood as intelligent education (Intelligent Education, IE) refers to the integration of AI technology into the education ecology, using AI technology as a means and tool to promote the automation and intelligence of the education and teaching process, improving the efficiency of education and teaching.

\subsection{Connotation and goal}

The basic connotation of IE is teaching students in accordance with their aptitude, realizing high-quality 
education sharing and lifelong learning. IE uses artificial intelligence and big data technology to accurately calculate students' learning ability foundation, internal subject tendency, thinking type, and interest development potential through deep learning, data mining, etc., and at the same time, according to the law of cognitive advancement and education of student growth, teaching students in accordance with their aptitude. With using network media IE can break through the time and space limitations of traditional education, and students can receive the same high-quality courses in different time and space, so as to realize the sharing of high-quality educational resources and citizens' lifelong learning. The core goal of intelligent education is to use intelligent means to achieve individualized development of students, and to help students improve their innovation ability and other literacy.

\subsection{The composition of intelligent education}

AI technology can be integrated into IE ecosystem ${ }^{[2]}$ including the teaching, learning, and management processes of education. Using big data technology, language intelligence, computer vision, and pattern recognition and emotion analysis as means to realize the intelligence of the education. IE is mainly composed of intelligent classrooms, intelligent resources, intelligent services and intelligent management.

(1) Intelligent Classroom: Intelligent classroom refers to a classroom that breaks through the traditional desks, chairs and blackboards, and uses intelligent hardware embedded with technologies such as the Internet of Things and cloud computing to construct a new type of classroom space. The construction of intelligent classrooms can create an open, shared, interactive and collaborative intelligent teaching environment.

(2) Intelligent Resources: Intelligent resources refer to the provision of rich data resources for the teaching process, using intelligent software and hardware equipment to display teaching content through text, pictures, audio, video and virtual simulation and other multi-modal information, so as to strengthen students' abstract concepts intuitive understanding.

(3) Intelligent Service: Use block-chain, big data and other technologies to track and record the data in the student's learning process, and provide personalized teaching guidance and services for different students based on data analysis, sentiment analysis, and education and teaching rules. The data in the learning process of students includes knowledge-related and emotional cognition. Based on knowledge-related data, it can provide students with personalized customization of learning content; based on emotional cognition-related data, it can help teachers understand the emotional dynamics of students in time. Pre-judge the students whose emotions and cognitive data tend to fluctuate in a timely manner, and notify teachers to intervene and care to avoid psychological problems for students.

(4) Intelligent Management: Intelligent management refers to the realization of intelligence in the teaching management process, optimizing the teaching management mode, reducing the repetitive labor in the teaching management of teachers, and transferring the repetitive and mechanical operations in the teaching management process to the intelligent teaching management system to improve management effectiveness. Save teachers' time in teaching management, and provide more time and space for teachers' personal development, creative activities, and emotional attention to students.

\subsection{Comparison with the traditional education}

Intelligent education is different from the private school education in the agricultural society and the school class education in the industrial society ${ }^{[3]}$. It is a brand-new education model that emerges with the empowerment of artificial intelligence in the field of education. Great changes have taken place in the 
teaching environment, teacher roles, teaching models, and teaching resources in intelligent education. The following table lists several comparisons between traditional education and intelligent education.

Table 1. Comparison with the Traditional Education

\begin{tabular}{ccl}
\hline Element & Traditional Education & \multicolumn{1}{c}{ Intelligent Education } \\
\hline Environment & Physical Classroom & Network virtual space without geographic limitation \\
\hline Role of teachers & $\begin{array}{c}\text { Knowledge transmitter; } \\
\text { Face-to-face teaching }\end{array}$ & $\begin{array}{l}\text { A guide to improve students' ability; } \\
\text { Human-computer collaborative teaching }\end{array}$ \\
\hline Teaching mode & $\begin{array}{c}\text { Indoctrination teaching; } \\
\text { Standardized teaching }\end{array}$ & $\begin{array}{l}\text { Inquiry teaching; } \\
\text { Personalized teaching }\end{array}$ \\
\hline Teaching Resources & Text, pictures & Text, video, radio, 3D imaging, VR \\
\hline Teaching Interaction & Face-to-face Interaction & $\begin{array}{l}\text { Realtime Interaction; } \\
\text { human-machine Interaction; } \\
\text { Human-machine-human Interaction }\end{array}$ \\
\hline
\end{tabular}

From the comparison content in Table 1., it can be seen that the Intelligent Education makes full use of the advantages of AI technology to expand traditional education and teaching in space and time. At the same time, unlike previous information education, Intelligent Education can achieve students' individualized education and characteristic education better. The realization of personalized education mainly relies on the application of big data technology in teaching. Through the recording of a large amount of students' learning data and growing data, the characteristics of students' learning path and interest are analyzed. According to each student's different points of interest, specialties carry out corresponding knowledge push in the learning environment, and then achieve personalized development.

\section{Problems and response strategies}

Intelligent education is the application of AI technology in the education field. It operates according to human design, contains human goals, and presents human values. Education is the foundation of the country and is related to the destiny of mankind. In the design and application of IE, attention should be paid to the relationship between students and AI things, the emotions in IE, the ethics and morals in IE, and the supervision of teaching content in IE.

\subsection{Emotional problems in IE}

The complete process of education includes cognitive education and emotional education ${ }^{[4]}$. Emotional teaching refers to the creation of a harmonious teaching environment that is conducive to student learning in classroom education, giving full play to the positive role of emotional factors, and keeping students happy in the learning process Mood, stimulate their thirst for knowledge and exploration, in order to obtain a better teaching effect. Using artificial intelligence's emotion recognition and other technologies to actively and positively guide students in the process of intelligent education can create a good teaching environment and achieve better teaching results. The introduction of emotion analysis, emotion interaction, emotion recognition and other technologies in intelligent education can prevent students from becoming problemmaking machines under the guidance of intelligent objects, avoid student mechanization, and fill up the deficiencies of emotional education in intelligent education. 
Correctly handling the emotional problems in the education and teaching environment is not only a positive help for students' learning progress, but also has a very important role for students' physical and mental health. Schools and other educational places are the most important places for students to do activities outside of their homes. Students' behavior during school can reflect their psychological conditions. Intelligent education ${ }^{[5]}$ can analyze the behavior data of students during school, and provide early warning to teachers and parents for some abnormal behaviors, and remind teachers to give special attention and guidance to students with abnormal behavior data, so as to avoid students' psychological problems.

\subsection{Ethics in intelligent education}

Wendell Wallach, Director of the Science and Ethics Department of the Bioethics Center at Yale University, said, "Technology enters the driver's seat and becomes the determinant of human destiny. If the system fails, who will bear the responsibility?" He also pointed to home robots and automated financial systems. It has been able to affect human life and will have unpredictable ethical consequences ${ }^{[6]}$. Humans should act as soon as possible to allow the development of ethics and technology to proceed simultaneously. As the educator Xingzhi Tao said, "The destiny of the children is in the hands of the teacher, and the destiny of the nation and mankind is in the hands of the teacher." Education is related to the destiny of individuals, nations and even human beings. The ethical and moral issues of intelligent education should be accelerated. Mentioned the agenda of discussions from all walks of life.

On December 16, 2019, the press conference held by the Ministry of Education pointed out that the requirements for teacher ethics and style should be integrated into all aspects of teacher management, strict requirements for teacher ethics and style, highlighting the first standard of teacher ethics and style, and for serious violations ${ }^{[7]}$. Teachers are prohibited from teaching for life. In intelligent education, artificial intelligence technology is used to realize virtual teachers. In the process of teaching, virtual teachers should follow certain ethics and convey correct moral concepts. Social psychologist Maslow said, "Science is a creation of human beings, not an active, non-human thing; science arises from human motivation, and its goals are human goals." Therefore, in the design of intelligent education systems, Development and other links need to embed correct and positive moral values, worldwide views, etc. into intelligent things.

\subsection{Policy supervision issues}

Education is the carrier of the inheritance and development of human culture and values, and a means to improve the quality of the people and strengthen the national competitiveness. Education has always been at a very important position in the history of human development. The teaching content involved in intelligent education must be under strict supervision ${ }^{[8]}$ to ensure that students acquire the correct knowledge and value orientation. The supervision of intelligent education needs to start with the underlying software, that is, start with the basic content of the intelligent education system, strictly supervise the design and development of corresponding products ${ }^{[9]}$, conduct content audits for intelligent education products before applying them, and resolutely deal with products with unqualified content can't enter the field of intelligent education applications.

\section{Conclusions and prospects}

\subsection{Conclusions}

The development of technology has changed the way of human life, and the integration of artificial intelligence technology is reshaping the form of education. Intelligent education has enriched the traditional education ecology, but it has not changed the dominant position of teachers and students in education ${ }^{[10]}$. The main relationship in education is the teacher-student relationship. In the future development of 
intelligent education, people will still be the main body of education. As new technologies and new means, intelligent things will form an education ecology that coexists with human teachers and students. In the new education ecology, people-oriented, inheriting culture and creating knowledge should be adhered to the nature of education to cultivate talents.

\subsection{Prospects}

(1) Human-computer interaction: The more efficient, smooth and natural communication between students and intelligent things in intelligent education depends on the improvement of humancomputer interaction technology. Human communication is based on natural language and revolves around semantics, while machine communication is databased and loyal to data. Human-computer interaction technology should build semantic-based interaction, focusing on digital processing of semantics carried by text symbols and voice signals.

(2) Emotional perception and calculation: People are different from intelligent things. People have emotions, they understand emotions, they need emotions, and people can respond to emotions. It is difficult for people to fully mechanize knowledge exchange without emotions. Through emotional perception and computing technology, human-computer interaction in intelligent education can be handled humanely, a good learning atmosphere can be built, and teaching efficiency can be improved.

(3) Big data technology: Big data technology can help characterize students' individual learning plans, but it will also bring about the security of students' personal information. At the same time, personalized push based on big data can easily lead to the emergence of blind spots in learning information. These problems need to be comprehensively considered while applying technology. At the same time, attention should be paid to data security issues in the development and application of intelligent education. It is necessary to rationally use big data to analyze students' learning behaviors and fully realize the protection of students' private information.

(4) Dual-teacher collaborative intelligent education: In IE, intelligent things can replace some of the functions of teachers, but they cannot replace the existence of teachers. Intelligent things can be called AI Teachers, and teachers can be called Human Teachers. Intelligent education requires collaboration and complementarity between two teachers. This kind of collaboration is embodied in the two links of teaching and management. Human teachers can make full use of the advantages of emotional cognition, moral feelings, and humanistic qualities to provide creative guidance and emotional care to students in teaching; they can take the initiative to supplement the functions of artificial intelligence teachers in teaching management. Human-computer collaboration and common development will be the future development direction of intelligent education.

\section{Funding}

This research was supported by the Chinese Ministry of Education-China Mobile Scientific Research Fund 2020 with the context of the MCM2020-4-2 project (Research on applications of the block-chain technology in education).

\section{Disclosure statement}

The authors declare that there is no conflict of interest. 


\section{References}

[1] Carbonell JG, Gil Y, 1990, Machine Learning: An Artificial Intelligence Approach, Morgan Kaufmann Publishers Inc., Ch. Learning by Experimentation: The Operator Refinement Method, 3: 191-213.

[2] McLaren TB, Van Gog C, Ganoe M, et al., 2016, The Efficiency of Worked Examples Compared to Erroneous Examples, Tutored Problem Solving, and Problem Solving in Computer-Based Learning Environments, Comput. Hum. Behav. 55: 87-99.

[3] Najar A, Mitrovic B, McLaren, 2016, Learning with Intelligent Tutors and Worked Examples: Selecting Learning Activities Adaptively Leads to Better Learning Outcomes than a Fixed Curriculum, User Modell. User-Adapted Interaction 26 (5): 459-91.

[4] Hershcovits D, Vilenchik K, 2020, Modeling Engagement in Self-Directed Learning Systems Using Principal Component Analysis, IEEE Trans. Learn. Technol. Learn. Technol. 13 (1): 164-71.

[5] Dodero JM, García-Peñalvo FJ, et al., 2016, Development of E-Learning Solutions: Different Approaches, A Common Mission, Revista Iberoamericana de Tecnologias del Aprendizaje 9 (2): 72 80.

[6] Baker RSJ, 2007, Modeling and Understanding Students' Off-Task Behavior in Intelligent Tutoring Systems. In Proceedings of ACM CHI: Computer-Human Interaction, 1059-68.

[7] Amalathas S, Mitrovic A, Saravanan R, et al., 2010, Developing an Intelligent Tutoring System for Palm Oil in ASPIRE. Proceedings of the 18th International Conference on Computers in Education, Nov. 29-Dec. 3, AsiaPacific Society for Computers in Education, Putrajaya, Malaysia, 101-3.

[8] Fournier-Viger P, Nkambou R, Mephu E, 2010, Building Intelligent Tutoring Systems for Ill-Defined Domains. In: Advances in Intelligent Tutoring Systems, Nkambou, R., R. Mizoguchi, and J. Bourdeau (Eds.). SpringerVerlag, Berlin, Heidelberg, 81-101.

[9] Brunstein A, Betts S, 2009, Anderson JR Practice Enables Successful Learning Under Minimal Guidance. J Educ Psychol 101:790-802. 